\title{
Estimating the Cost of Saving Electricity Through U.S. Utility Customer-Funded Energy Efficiency Programs
}

\author{
Ian M. Hoffman, Charles A. Goldman, Gregory Rybka, Greg Leventis, Lisa Schwartz, Alan H. \\ Sanstad, Steven Schiller \\ Lawrence Berkeley National Laboratory \\ June 2016
}

Keywords: energy efficiency, ratepayer-funded efficiency, demand-side management, cost of saved energy, savings target, emissions reduction

\begin{abstract}
The program administrator and total cost of saved energy allow comparison of the cost of efficiency across utilities, states, and program types, and can identify potential performance improvements. Comparing program administrator cost with the total cost of saved energy can indicate the degree to which programs leverage investment by participants. Based on reported total costs and savings information for U.S. utility efficiency programs from 2009 to 2013, we estimate the savings-weighted average total cost of saved electricity across 20 states at $\$ 0.046$ per kilowatt-hour (kWh), comparing favorably with energy supply costs and retail rates. Programs targeted on the residential market averaged $\$ 0.030$ per $\mathrm{kWh}$ compared to $\$ 0.053$ per $\mathrm{kWh}$ for non-residential programs. Lighting programs, with an average total cost of $\$ 0.018$ per $\mathrm{kWh}$, drove lower savings costs in the residential market. We provide estimates for the most common program types and find that program administrators and participants on average are splitting the costs of efficiency in half. More consistent, standardized and complete reporting on efficiency programs is needed. Differing definitions and quantification of costs, savings and savings lifetimes pose challenges for comparing program results. Reducing these uncertainties could increase confidence in efficiency as a resource among planners and policymakers.
\end{abstract}

\section{Introduction}

Demand-side energy management policies and programs, particularly those focused on end-use energy efficiency, originated in the 1970s and have been widely adopted in the United States and in other OECD countries. In recent years, interest in demand-side approaches in the U.S. has increased both for cost effectively meeting electricity and natural gas needs and for reducing carbon dioxide emissions from the electric power sector. For example, six American states have 
mandates to acquire all cost-effective energy efficiency in utility resource planning, and fifteen states have enacted long-term, binding energy savings targets to be achieved through end-use efficiency. ${ }^{1}$ Many more states assigned savings targets specific to each state-regulated efficiency program administrator. In 2014, U.S. energy efficiency program administrators who manage utility customer-funded efficiency programs spent about $\$ 6.9$ billion on electric and gas energy efficiency programs (CEE 2015), with spending projected to increase significantly by 2025 to $\$ 9$ billion to $\$ 15$ billion (Barbose et al. 2013).

These utility customer-funded efficiency programs are overseen by state regulators and administered by more than 100 different entities (utilities, state energy agencies, non-profit and for-profit third parties). Policymakers, regulators, administrators and implementers rely on information about lifetime costs and savings of these customer-funded efficiency programs to assess efficiency's potential, to design and implement programs in a cost-effective manner or to improve program cost effectiveness. Given both the current scope of efficiency programs and the expected growth in funding for existing and new programs (Barbose et al. 2013), accurate assessments of program costs and impacts is an increasingly important policy and regulatory priority. However, while analysis of both the energy-saving impacts and the costs of efficiency has been ongoing since programs of this type first appeared in the 1970s, it remains challenging and incomplete. The most important reason is that the data requirements for rigorous cost assessment are considerable and difficult to meet in practice.

This paper presents initial results of a project aimed at addressing this problem. Lawrence Berkeley National Laboratory (LBNL) has created the Demand-Side Management Program

\footnotetext{
${ }^{1}$ California, Connecticut, Massachusetts, Rhode Island, Vermont and Washington have enacted legislative statutes that require investor-owned utilities to acquire all cost-effective energy efficiency while AZ, CA, CO, HI, IL, IN, MD, MI, MN, MO, NM, NY, OH, PA and TX have passed energy efficiency resource standards.
} 
Impacts Database, containing information on the results of utility-funded end-use energy efficiency programs submitted by more than 100 efficiency program administrators to state regulators for the 2009 to 2013 period. It includes cost and energy savings data on more than 1,700 unique programs over one or more program years, for a total of more than 6,000 programyears of data from 36 U.S. states.

This paper describes an analysis of the costs and impacts of U.S. efficiency programs using a subset of these data for which information is most complete, corresponding to 2,100 program years across 20 states. We have constructed the most comprehensive estimates to date of the full cost of saving energy through efficiency programs that are funded by customers of investorowned electric utilities. We account for energy-saving investments made by efficiency program administrators and by program participants. Our estimates are based on total cost of saved energy, a metric that resource planners, regulators and stakeholders can use for assessing the relative costs among electric energy efficiency programs and between efficiency and energy supply investments.

The paper is organized as follows. We begin by reviewing the history and current status of efficiency program impacts and cost assessment. We then discuss several cost metrics associated with utility efficiency program analysis. We then turn to describing the data, providing details on sources, how the dataset used for this particular analysis was constructed, quality issues and how they have been addressed, as well as fundamental data limitations that bear on our analysis. We then present and discuss our estimates of the total cost of saved energy in utility programs for the U.S. overall as well as by national market sector (residential, commercial, industrial) and by program type (e.g., residential whole-home programs, commercial retro-commissioning, commercial/industrial custom rebate program). In this section we also compare the differences 
between program administrator costs alone and the total cost of saved electricity, which includes participant costs as well. In the final section, we summarize our key results and discuss their policy implications.

\section{Previous and Current Related Work}

Efforts to develop performance metrics for energy-efficiency programs, particularly to quantify the cost of saving energy, began in the late 1970s (e.g., Sant 1979). Initially, researchers and analysts developed a "levelized" cost of lifetime energy savings metric, in which costs were amortized over the economic life of efficiency measures. Conceptually, this levelized cost of efficiency treats measure costs as though they were financed with a loan, with a repayment term equal to the economic life of the measure. The key motivation for this approach was to enable comparison of a utility's efficiency investment costs with its levelized cost of investing in and operating a power plant. Meier $(1982,1984)$ and others refined these methods and applied them to construct conservation "supply" curves for individual measures.

These early calculations of levelized costs were based on the costs of purchasing and installing more efficient measures and so are best understood as a means of estimating technical and economic potential ex ante: What measures can deliver what quantity of savings at an incremental measure cost below the price of energy supply? However, as utility programs proliferated in the 1980s, the reports of program administrators added a new dimension to understanding the costs of energy efficiency by providing the first substantial data on the costs of administering programs. These costs included the cost of designing and administering the programs, identifying energy saving measures for customers, promoting measures, providing incentives and verifying the savings, among other expenses. The more common costperformance metrics for program administrators were the costs of first-year and lifetime savings, 
from the perspective of the utility. A number of economic, cost-effectiveness screening metrics also were developed during this period in order to establish that programs or measures were cost effective, i.e., that the monetized benefits of the efficiency actions exceeded their costs, so that utilities and their customers could weigh competing investments (Krause and Eto 1988).

However, numerous researchers noted the incompleteness, inconsistency and lack of standardization in reported program data (e.g., Hirst and Goldman 1990) and the implications for estimating program costs and using the results in utility planning. For example, Joskow and Marron (1992) reviewed costs and estimated savings for 12 U. S. utility efficiency "portfolios"sets of programs - and concluded that “...computations based on utility expectations could be underestimating the actual societal cost [of efficiency programs] by a factor of two or more on average." In a study conducted in response, Eto et al. (1996) adopted Joskow's and Marron's analytical framework and applied it to twenty U. S. commercial lighting efficiency programs. Eto et al. found that the reported data for these programs were subject to a number of uncertainties including omitted costs - but concluded that, when these uncertainties were addressed and the costs thoroughly accounted for, the programs' benefits exceeded their total costs.

In the early 1990s, some efforts were made to address these problems and calculate the full costs of energy efficiency for comparison with the utility costs of energy supply (e.g., Eto et al. 1994, 1996). These efforts required substantial effort to obtain data beyond that contained in standard administrator reports, including oral interviews with utility DSM staff. Researchers since have tended to rely upon the lifetime or levelized administrator costs of saved energy as the primary metrics of program cost performance.

These efforts have been useful for indicating overall trends and costs of efficiency. Recently, 
several organizations have collected and analyzed the cost per unit of end-use energy savings by utility customer-funded efficiency programs using various methods and definitions. For example, since 2006, the Consortium for Energy Efficiency (CEE) has issued annual industry reports that survey efficiency program administrators and report on budgets, expenditures and savings. ${ }^{2}$ The Northeast Energy Efficiency Partnerships' (NEEP) Regional Evaluation, Measurement and Verification Forum (EM\&V Forum) supports the development and use of common, consistent protocols to evaluate, measure, verify, and report the savings, costs, and emission impacts of energy efficiency. The EM\&V Forum has developed the Regional Energy Efficiency Database (REED), launched in early 2013, which includes data from eight states, soon to be nine states and the District of Columbia. REED was informed by the Forum's “Common Statewide Energy Efficiency Reporting Guidelines," which were adopted by the Forum's Steering Committee in 2010. ${ }^{3}$ The U.S. Energy Information Agency (USEIA) has for many years collected data on a voluntary basis on energy efficiency programs administered by electric utilities, reported in its "861 Form". The USEIA (2013) has also released a "State Energy Efficiency Program Evaluation Inventory" that supported the National Energy Modeling System (NEMS) and provided information from state-mandated energy efficiency program evaluations. ${ }^{4}$ The American Council for an Energy-Efficient Economy (ACEEE) has also conducted industry surveys for many years and conducted a 14-state study of the cost of energy saved through efficiency programs (Friedrich et al. 2009).

Our contribution to this literature is three-fold. First, our analysis is based upon information drawn from the LBNL database, which is both the most complete dataset of its kind and

\footnotetext{
${ }^{2}$ See http://www.cee1.org/annual-industry-reports.

${ }^{3}$ See http://neep.org/emv-forum/about-the-emv-forum/index

${ }^{4}$ See http://www.eia.gov/efficiency/programs/inventory/
} 
incorporates extensive work directed toward maximizing quality and consistency. Second, we analyze energy efficiency impacts and costs across the complete range of scale, from national down to program level. Third, we extend the usual focus of this type of study by examining both program administrator and participant costs, jointly and in relative terms. In the next section we define and discuss our cost metrics.

\section{The Cost of Saved Energy: Metrics}

There are two basic categories of costs associated with utility energy efficiency programs. The “program administrator's cost" accounts for expenditures in planning, designing, and implementing a program and providing incentives to market allies and end users to take actions that result in energy savings. The "participant cost" is the expenditure undertaken as a result of the program and incurred directly by the participant - e.g., the consumer purchase cost of energy-efficient appliances, equipment or measures net of any program paid incentives, such as rebates. Knowing the program administrator cost of saved energy enables assessments of efficiency resources from the economic perspective of the utility, and so is useful to utility program administrators and state regulators.

Nevertheless, as we noted, the program administrator cost of saved energy metric has been subject to the criticism that it underestimates the full costs of energy efficiency. This can be addressed by accounting for both program administrator and participant costs. Understanding these combined costs of energy efficiency programs is important, for example, in comprehensive energy policy analysis and planning - including assessment of the marginal cost of abating $\mathrm{CO} 2$ emissions - when decision-makers require estimates of all costs associated with all potential options and strategies. Policymakers need to know where utility customer dollars are most effectively spent to satisfy loads and other objectives, such as mitigating air emissions. 
In this paper we base our analysis primarily on this comprehensive total cost perspective and focus on electricity programs specifically. Our work is based on the following metric. Let $r$ be the discount rate, and $N$ the lifetime of the measure, program, or portfolio in years. For programs or portfolios, this lifetime is estimated as the sales-weighted lifetime of measures or actions promoted by the program, or the constituent programs. Then the "total cost of saved electricity" (TCSE) is defined as

Total Cost of Saved Electricity = $\frac{\text { Capital Recovery Factor * (Program Administrator Costs }+ \text { Net Participant Costs })}{\text { Annual Energy Savings (in } k W h)}$,

where the Capital Recovery Factor (CRF) is

$$
C R F=\frac{r(1+r)^{N}}{(1+r)^{N}-1}
$$

That is, the total cost of saved electricity constitutes the combined administrator and participant costs, levelized over the average savings lifetime of the energy efficiency actions promoted by each program type (or market sector) divided by the annual electricity saving. ${ }^{5}$

It is intended to be comparable to the levelized cost of energy supply, which is analogously defined for capital costs of electricity power plants. The total cost of saved electricity may be used by utility planners, regulators and other stakeholders for screening potential investments in energy efficiency jointly with those in power generation. Both the choice of discount rate and the estimation of lifetimes are discussed later in the paper.

\footnotetext{
${ }^{5}$ It is important to recognize that some efficiency programs include measures designed to save electricity and yet also have the effect of reducing need for heating fuels (e.g. insulation and high-efficiency windows may reduce demand for air conditioning as well as space heating). Thus benefits are greater for these programs/measures than if they only result in electricity savings.
} 
A critical distinction in efficiency impact analysis is that between so-called "net" and "gross" savings (NAPEE 2007). While definitions vary, these terms reflect the fact that energy savings from actions taken by participants that elect to participate voluntarily in these programs may not be due specifically to the program itself. Gross savings are the changes in energy consumption by program participants, regardless of the cause. Net savings are those that can be attributed to the program specifically. An important example of the difference between the two is participant self-selection, or "free-riding." This refers to the pre-existing propensity of those who enlist in programs to take efficiency-increasing actions even in the absence of the program. The analysis in this paper deals with gross energy savings, primarily because net savings are not widely reported, and when they are, inconsistencies in the definition and estimation of net-to-gross ratios add considerably to the uncertainties already embedded in estimates of gross energy savings. A more extensive discussion of this methodological choice may be found in Billingsley et al. (2014).

\section{Data Sources, Processing, and Issues}

In this section, we describe the methodology for collecting, standardizing and validating the data analyzed and highlight several documentation and analysis challenges: (1) incomplete or inconsistent data reporting; (2) issues in reporting of annual and lifetime savings of efficiency measures; and (3) defining and reporting participant costs.

Annual reports prepared by program administrators are the most comprehensive, consolidated repository of efficiency program data. For the analysis in this paper, we identified program administrators who reported total costs at the program level, and collected program-level cost and impacts data from annual reports to state regulators or similar sources. By this criterion, the 
LBNL Database includes information from one or more program administrators reporting total costs in 20 states, which are mapped by the degree of data coverage in Figure 1.

States and program administrators vary widely in the level of rigor that they apply in estimating claimed savings and the frequency and fidelity with which they update those values as evaluations of actual savings are completed. ${ }^{6}$ Broadly speaking, there are two methods for estimating energy savings from utility efficiency programs. Claimed savings are calculated by multiplying the number of efficiency measures installed, or actions taken, under a program by ex ante estimates of the per unit savings. These estimates are often documented in a "technical reference manual" of efficiency measures and actions. ${ }^{7}$ These ex ante estimates are derived using various methods including building energy computer simulation models, deemed calculation methods and deemed savings approaches. Impact evaluation savings estimates are calculated by measuring program participant energy use ex post and comparing this to counter-factual estimates of what this energy use would have been in the absence of the program. Some states and program administrators attempt to incorporate results from impact evaluations into the savings estimates in their technical reference manual. The savings data in the LBNL database, including those used for this analysis, are overwhelmingly of the "claimed" type, taken from annual reports filed by efficiency program administrators with state regulators.

\footnotetext{
${ }^{6}$ Program administrators also differ widely in their assumed baselines - whether the level of energy performance assumed prior to installing a measure or taking another efficiency action is based on common practice, building energy code or even a tiered or dual baseline that changes over the savings lifetime of a measure.

${ }^{7}$ A technical reference manual (TRM) is a term of art that describes a document or database of standardized assumptions and ex-ante values for determining the savings from well-defined energy efficiency measures installed and operated under defined conditions (Schiller, Goldman and Galawish 2011). A TRM may include “...the methods, formulas, and default assumptions used for estimating energy savings...from energy efficiency measures and projects." (ERS 2014) In some areas (the Pacific Northwest), TRMs are administered and managed on various geographic scales, from regional organizations (e.g., the Regional Technical Forum in the Pacific Northwest) to statewide efforts, maintained by consultants selected by state regulators or program administrators. In other places, individual program administrators maintain less formalized measure lists with deemed savings and measure lifetime estimates for their own use.
} 
We characterized programs by sector, subsector, program implementation type and technology so as to compare programs on a consistent basis and to better define program savings lifetimes that are a critical input to the cost of saved energy (Billingsley et al. 2014). We also followed an internal quality control and quality assurance (QAQC) protocol that included internal flags for aberrant values and, once a researcher was finished entering data for a state, extensive spotchecking by a second researcher. The data input and QAQC process helped identify some issues that we then raised with program administrators. In general, we took all data reported by program administrators as given. The results of LBNL's calculations are therefore highly dependent on values as reported by program administrators.

Total cost data present unique challenges for data collection and input. For each annual report, LBNL staff ascertained how the program administrator defined total resource costs and participant costs and took steps to standardize the cost data. Adjustments were made to fill in missing data, and already-discounted costs were changed to non-discounted values. With these steps, we were able to standardize more than 2,100 program years of total cost data for administrators in 20 U. S. states.

\subsection{Issues with data quality, consistency, and availability}

Efficiency program data analyzed in this study are subject to several long-standing issues that impact both the cost and savings terms of the cost of saved electricity equation (Hirst and Goldman 1990, Joskow and Marron 1992, Eto et al. 1994, Billingsley et al. 2014). These include: 
Incomplete and Inconsistent Data Reporting: Most states with large-scale utility customerfunded efficiency programs require administrators to perform benefit-cost tests that require knowledge of total costs. Yet fewer than half of program administrators actually report those total costs or data from which they might be derived. Thus, the analyses presented here are based on data from 20 states for which data for computing program-level total costs were available or could be obtained with direct queries. ${ }^{8}$

Estimation and Reporting of Annual and Lifetime Savings of Measures: Methods for estimating the annual per unit savings for efficiency measure or actions - and the number of years that those savings last - vary among program administrators and the consultant studies that often provide annual savings and measure lifetime estimates.

Variability in estimates for measure lifetimes, and often annual savings as well, can arise from multiple sources (Hoffman et al. 2015):

- Limits or mandated caps on measure lifetimes at 10 or 15 years (e.g., Texas and Pennsylvania);

- Differences among program administrators in evaluation, measurement and verification $(\mathrm{EM} \& \mathrm{~V})$ approach and level of effort, as well as underlying assumptions and frequency of updating measure lifetimes and savings estimates;

- Differences in the types of efficiency project applications (e.g., retrofit installation vs. replace on burnout vs. new construction, which may have different baselines for lifetimes);

\footnotetext{
${ }^{8}$ Data were obtained directly from one or more program administrators in a few states, e.g., Oregon and North Carolina.
} 
- Differences in geography, building stock and environmental conditions-e.g., water heaters in regions with highly alkaline water have shortened lifetimes (Messenger 2014); icy and snowy conditions can shorten lifetimes for exterior lighting;

- Use of dual or dynamic baselines for energy consumption;

- Extent to which estimates of savings for a high-efficiency measures are disaggregated by market segment (e.g., savings from lighting measures for commercial sector vs. savings estimates that are based on operating regimes or operating hours for specific market segments (e.g., a lighting retrofit measure installed in a school, retail store, or hospital)

Defining and Reporting Participant Costs: Participant costs are those incurred directly by program participants, excluding incentives provided by the program and can be determined directly or indirectly. For example, participant costs can be identified directly by analyzing receipts, invoices or other transaction records of participants, retailers or contractors, often as a precursor to setting and awarding an incentive to the participant.

The indirect approach is more common and involves estimating the cost of the efficiency measure and then subtracting any incentives, leaving the participant contribution. However, reliable cost data are often not available and distilling the costs of many different equipment or appliance models into a single measure cost (e.g., a generic Energy Star-qualified refrigerator) can be challenging. Definitions of the cost of a measure can differ. Many program administrators define measure costs simply as the incremental cost - that is, the additional increment of cost of 
the high efficiency measure compared to the cost of a measure of standard energy performance. ${ }^{9}$ Other program administrators define measure costs by program type or application. Incremental measure costs are used for some program types, such as programs that reduce the cost of installing an efficient air conditioner in a new home (rather than a standard, less efficient model) or to replace one that is broken beyond economic repair (replace on burnout)

Other costs, such as program participant transactions costs, would in theory also be included in the total cost of saved energy. However, these ancillary costs are not reported by any of the program administrators in our sample and thus, are not incorporated in this analysis (see Hoffman et al. (2015) for further discussion).

\subsection{Discounting and Cost Indicators}

We used a $6 \%$ real discount rate as an approximation of the weighted average cost of capital (WACC) for an investor-owned electric utility. ${ }^{10}$ The $6 \%$ value is intended to be a proxy for a nominal discount rate in the range of $7.5 \%-9 \%$, typical values that we have encountered for a utility weighted average cost of capital. This utility weighted average is the most common discount rate for economic screening of efficiency programs in practice.

The focus of our analysis is savings-weighted average and median costs, with findings reported in the following section. The metric for gauging the U. S. national, full cost of saved energy is the savings-weighted average for the entire, aggregate portfolio of efficiency programs, totaling

\footnotetext{
${ }^{9}$ The incremental cost of an efficient energy-using device, conditioning system or building shell component is limited to the additional cost associated with its energy-saving features and does not include other desirable features (e.g., a refrigerator's stainless steel finish or the window's attractiveness). Isolating the increment in costs solely associated with what makes a measure more efficient can be difficult. One accepted method uses statistical regression to separate the efficiency premium from other cost components; however, this method requires large sample sizes given the number and diversity of products and features in the market.

${ }^{10}$ The WACC is the average of the cost of payments on the utility's debt (bonds) and its equity (stock), weighted by the relative share of each in the utility's funds available for capital investment. We used a real discount rate because our cost data are in constant - i.e., inflation-adjusted - dollars.
} 
more than 2,100 program years. This savings-weighted average total cost of saved energy is calculated using costs for all programs over the average lifetime of savings at the stipulated level of analysis (e.g., nation, state, sector, program), including programs for which no savings are claimed (e.g., residential audits or portfolio support programs). Larger programs can therefore have greater influence on the savings-weighted averages than smaller programs.

For each type of efficiency program, we also report savings-weighted averages and median values for the total cost of saved energy. These values are calculated based on the total cost of saved energy values for each individual program year and requires both cost and savings information. There are about 1,600 program years for which this information is available as programs are excluded for which no savings are achieved or claimed. The larger, all-inclusive dataset contains some "programs" that actually are not efforts to save energy per se, but rather are the costs associated with administering a portfolio of programs (e.g., certain brand marketing, regulatory and overhead costs). Some program administrators allocate all of these costs down to the program level; others do not. The two savings-weighted averages capture this difference in cost-allocation and reporting practices.

Lastly, we report ranges of total costs of saving electricity as this metric varies widely from program to program. Illustrating this variability provides some helpful context for the averages and medians. In practice, there is considerable heterogeneity among energy efficiency programs in terms of design characteristics and implementation details. Moreover, each administrator operates in its own policy context while technical opportunities for efficiency investments depend in part on the building and equipment/appliance stock, climate, types of industrial facilities, and customer hurdle rates and preferences. Moreover, some program administrators are 
successful in engaging customers to participate because of program design, marketing, and/or information, while others struggle to get customer participation.

Given these factors and the idiosyncrasies of regulatory reporting, there can be large variation in the cost of saved energy for a given program type. At the program level in particular, we illustrate some of the variation in the data by calculating and depicting inter-quartile ranges - the middle 50\% of values (excluding the lowest and highest values). This middle range provides a sense of variability. However, all values for a given program or market sector or administrators in a state are included in determining savings-weighted averages and medians.

\section{Results: The Total Cost of Saved Electricity}

In this section we report our quantitative findings on the costs of electricity efficiency programs. We first summarize U. S. national results for all programs for which both program administrator and participant cost data are available, and then proceed to an in-depth analysis focused solely on programs with claimed savings.

\subsection{The National Total Cost of Saved Electricity Across All Programs}

Nationally, the total cost of saved electricity, weighted by the reported energy saved, was $\$ 0.046$ per kWh across all sectors and programs in our 2009-2013 data collection (see leftmost bar in Figure 2). For comparison, the American Council for an Energy Efficient Economy (Molina 2014) reported a savings-weighted average of $\$ 0.054$ per $\mathrm{kWh}$ (in 2011 dollars) for a smaller sample of program administrators in seven states. ${ }^{11}$

\footnotetext{
${ }^{11}$ Differences in assumptions and key inputs account for some of the difference in results. For example, Molina et al. (2014) used a slightly lower discount rate (5 percent vs. 6 percent real), included performance incentives for program administrators, reported all costs in 2011 dollars, and used net rather than gross energy savings. LBNL did not include performance incentives because they usually are not available at the time that spending and savings are reported in annual reports. If a $12 \%$ estimated national average for performance incentives (Hayes et al. 2011) were
} 
Figure 2 also shows corresponding levels of participant spending, with the average total participant cost of saved electricity about twice the program administrator cost of saved electricity $(\$ 0.023 / \mathrm{kWh})$ in our dataset.

The average total cost for all residential sector programs was $\$ 0.033$ per $\mathrm{kWh}$ (see Figure 2), about 40 percent lower than the average cost of saved electricity in the commercial, industrial and agricultural sector $(\$ 0.055$ per $\mathrm{kWh})$. Programs in the $\mathrm{C} \& \mathrm{I}$ sector nonetheless had a larger influence over the savings-weighted average than residential programs because of greater electricity savings (51 percent vs. 38 percent of total savings).

As shown in Figure 2, programs for low-income customers had a significantly higher total cost of saved electricity (determined almost entirely by the program administrator component), with an average of about $\$ 0.142$ per $\mathrm{kWh}$. Low-income programs had only a modest impact on the savings-weighted average value for all sectors, however, because they only accounted for about 1 percent of total savings for our sample of programs.

\subsection{The Total Cost of Saved Electricity for Programs with Claimed Savings}

The total cost of saved electricity for programs with claimed savings ranged fairly widely in all sectors (Figure 3). The third quartile value across all sectors was 250 percent higher than the first quartile value, with particularly wide ranges among low-income and residential programs. The

applied to all program years for the program administrators in this analysis that receive performance incentives, the U.S. average total cost of saved electricity would be $\$ 0.048 / \mathrm{kWh}$. If we adjusted our analysis to account for all of ACEEE's methodological differences for our sample of programs, then the levelized total cost of saved energy would increase to $\$ 0.051 / \mathrm{kWh}$ (compared to our reported estimate of $\$ 0.046 / \mathrm{kWh}$ ). 
breadth of these ranges is a product of many factors, including but not limited to the contexts in which the programs operate, diversity in measure mixes and program designs, and the program administrators' assumptions regarding measure lifetimes.

The median value of the total cost of saved electricity for programs in all sectors was much higher than the savings weighted average, at $\$ 0.069$ per $\mathrm{kWh}$. This difference reflects the fact that some programs that account for a large share of the overall savings in our sample have low total costs of saved electricity values, thus keeping the overall savings-weighted average low compared to the middle value of the dataset.

\subsubsection{Residential Sector Programs}

The comparatively low cost of savings in the residential sector to a significant extent reflects the relative impact of consumer product rebate programs that provide incentives for energy efficient lighting, appliances and consumer electronics and account for nearly two-thirds (65 percent) of the total savings in this sector (Figure 4). These programs delivered electricity savings in 20092013 at an average total cost of $\$ 0.021$ per $\mathrm{kWh}$ (Figure 4). Within this category, lighting programs - primarily for compact florescent lighting - had the largest influence on cost results, accounting for 57 percent of the savings in the residential sector with a savings-weighted average total cost of $\$ 0.018$ per $\mathrm{kWh}$. Without these lighting rebate programs, the total savings-weighted cost of saved electricity would have been $\$ 0.055 / \mathrm{kWh}$ for the residential sector $(\sim 70$ percent higher than the actual cost) and $\$ 0.054$ per kWh for all sectors (nearly 20 percent higher).

So-called residential "prescriptive" programs typically provide incentives for more efficient heating, ventilation and air conditioning (HVAC) systems, water heaters, and shell 
improvements (e.g., additional insulation, high-efficiency windows). Their savings-weighted average cost of saved electricity is $\$ 0.054$ per kWh. Multi-family retrofit and "whole-home" retrofit programs are more comprehensive - i.e., entail multiple efficiency measures for a given structure - and are more costly on average, \$0.071 and \$0.094 per kWh, respectively. Residential new construction programs tend to have high cost of saved electricity values on average (\$0.111 per $\mathrm{kWh}$ ), in part because building efficiency standards have captured some of the lower-cost efficiency opportunities.

The relative cost contributions provided by program participants varies widely for different types of residential programs. One example is "behavioral feedback programs," which provide households with periodic reports on the details of their electricity use and other information such as comparisons with the usage of similar households, and customized electricity-saving suggestions (e.g., on thermostat settings). Participants in these programs usually incur no costs, while those in other types contribute substantially -28 percent of total costs in multi-family retrofit programs, 36 percent in whole-home retrofit programs, and 59 percent in prescriptive programs (see (Figure 4).

It is also important to note the range in performance among types of programs. Figure 5 shows median values and the interquartile range in the cost of saved electricity values. The interquartile ranges vary by a factor of three to five among residential program types. The large range for whole-home retrofit and new home construction programs may reflect variability in the mix of measures, program maturity, knowledge and state of the market, and program design. For example, many of the whole-home retrofit programs (i.e., home energy upgrade) are relatively new programs, and thus may have significant start-up costs or be early in developing the 
necessary relationships with local contractors. Some new construction programs attempt to drive higher energy performance throughout the home, while other new construction programs are limited primarily to promoting certain high-efficiency equipment or appliances.

The savings-weighted average total cost of behavioral feedback programs was $\$ 0.057$ per $\mathrm{kWh}$ for the programs in our 2009-2013 dataset. These 32 programs (excluding pilots and other programs for which no savings are claimed) have an interquartile range of $\$ 0.038$ to $\$ 0.092$ per $\mathrm{kWh}$. By way of comparison, for three programs sponsored for multiple years by U.S. utilities, Allcott and Rogers (2014) reported a range of $\$ 0.032$ to $\$ 0.044$ per $\mathrm{kWh}$.

Several factors may account for differences in these results for behavior feedback programs. First, we report our results as a savings-weighted average for a larger sample of programs. In addition, some large behavior feedback programs in our sample (in terms of enrolled customers and aggregate savings) targeted broader groups of residential customers, were located in milder climates, or were located in territories where efficiency programs have been operating for many years. These programs have higher cost of saved electricity values and, having produced large savings relative to other behavioral feedback programs, have a strong influence on the savingsweighted average values. Second, most savings from behavioral feedback programs come from changes in customer behavior (e.g., turning out unneeded lights), with some savings resulting from installing more efficient lights or equipment that is discounted or rebated by other programs. To avoid double-counting savings, some program administrators allocate those savings to the other programs, which tends to increase the cost of saved electricity for the behavioral feedback program. 
The duration and persistence of savings are key factors influencing the total cost of saved electricity. In our dataset, all program administrator- estimated savings for behavioral feedback programs are based upon the assumption that the savings from actions taken by customers would last about one year. A recent meta-analysis (Khawaja and Stewart 2014) of studies of the five longest-running behavior feedback programs recommends using a measure lifetime of 3.9 years. Using that value, the savings-weighted average total cost of saved electricity for behavioral feedback programs with claimed savings would have been $\$ 0.017$ per $\mathrm{kWh}$, compared to the \$0.057 per kWh average based on a one-year measure life.

Behavioral feedback programs have limited effect on our overall results for total cost of saved electricity, because they only account for about 6 percent of total residential savings in our 20092013 dataset. However, this type of program has become increasingly common in the past several years, and so our results are a useful first benchmark for future assessments.

\subsubsection{Commercial, Industrial, and Agricultural Sector Programs}

Non-residential programs with claimed savings had an average total cost of $\$ 0.053$ per $\mathrm{kWh}$, with average values for most program types in a narrow band between $\$ 0.042$ per $\mathrm{kWh}$ and $\$ 0.063$ per kWh (Figure 6). The most common program types are prescriptive and custom rebate programs, with total costs averaging $\$ 0.045$ and $\$ 0.052$, respectively. Each of these two program types accounted for about one-third of non-residential claimed savings; other program types account for the remaining third of savings in the non-residential sector.

Programs that target electricity savings opportunities specifically in the government and institutional sector had a higher cost of saved electricity on average ( $\$ 0.085$ per $\mathrm{kWh})$. Some 
program administrators have implemented programs that specifically target the so-called "MUSH" - municipalities, universities, schools, and hospitals - market that includes state and local government facilities, universities and colleges, elementary-, middle-, and high schools, and hospitals. For example, in the 2009-2013 period, California utilities offered more than 80 of these programs, most of them collaborations with local governments. These California programs account for more than half of the savings in the MUSH category in the Database. The savingsweighted cost of saved electricity for government and institutional programs outside of California was $\$ 0.048$ per $\mathrm{kWh}$, closer in cost performance to the non-residential sector overall $(\$ 0.053 \mathrm{kWh})$.

On average, participant cost contributions tend to be higher share of total costs in non-residential efficiency programs compared to residential sector programs.. For example, in custom and prescriptive commercial/industrial rebate programs, on average, program administrators and participants split total costs 41 percent/59 percent and 42 percent/58 percent, respectively. Figure 7 shows that the ranges in cost performance tended to be narrower for most types of C\&I programs than for those in our sample of residential sector programs. For example, the interquartile range values vary by a factor of two for nearly all types of C\&I programs (except for programs that target MUSH market customers), compared to a factor of three to five among various types of residential programs.

\subsubsection{Total and Program Administrator Costs of Saved Electricity at the State Level}

Figure 8 summarizes the total cost of saved electricity for each state in which one or more program administrators report sufficient program data. The total cost across all programs for which data could be collected in a given state, weighted by the energy saved, ranged from about 
$\$ 0.03$ per kWh for programs in New Mexico and Maine to $\$ 0.079$ per $\mathrm{kWh}$ in Massachusetts. The savings-weighted average was $\$ 0.046$ per $\mathrm{kWh}$ (denoted by the red dotted line) for all programs in our sample. The ratio of program administrator spending to participant spending also varies widely by state (Figure 8).

Many factors are likely to influence the total cost of saved electricity at the state level (Billingsley et al. 2014), including but not limited to the following:

- Policy objectives and context (e.g., acquiring all cost-effective efficiency; rising savings targets required by an Energy Efficiency Resource Standard)

- Program planning requirements (e.g., cost-effectiveness screening practices, avoided supply costs)

- Technical opportunities (e.g., characteristics of the existing building/housing stock and equipment)

- Program administrator performance and motivation

- Program scale

- Technical resources and approach used to evaluate, measure and verify savings (see subsection below)

- Electricity prices (e.g., impact on economic payback times for efficiency investments)

- Labor and materials costs.

For example, Hawaii and Massachusetts are at the upper tier for average cost of saved electricity values in this study. Retail electricity rates are above the national average in both states. 
Participating customers in Hawaii, with the highest retail electricity rates in the nation, are contributing a larger share of total costs than in most states. Program administrators in Massachusetts have implemented efficiency programs for more than 25 years, capturing much of the lowest-cost technical opportunities. Massachusetts also has a legislative mandate to pursue all cost-effective energy efficiency.

\subsubsection{Sensitivity of the Total Cost of Saved Energy to Program Savings Lifetimes}

One of the key factors that influences the total cost of saved energy is the estimated lifetime of measures installed in efficiency programs. Savings lifetimes can vary among efficiency programs for two general reasons: (1) variability in the design and delivery of efficiency programs (which in turn may influence the mix of measures offered or adopted by customers); and (2) differences in the program administrators' assumed lifetimes for individual measures, potentially arising from different EM\&V approaches. Table 1 shows the variability in reported savings lifetimes for various types of efficiency programs in the LBNL DSM Program Impacts database.

All else being equal, the cost of saved energy is lower if savings for a given measure in a program are estimated to last over a longer lifetime. Table 1 shows the range in program lifetimes for various types of programs (e.g., $25^{\text {th }}$ and $75^{\text {th }}$ percentiles and the averages for the sample of programs). ${ }^{12}$ Figure 9 shows the impact on the total cost of saved energy values when different savings lifetimes are used for each program type: shorter lifetimes (i.e., the first quartile of values in the LBNL DSM Program Database), average lifetimes, and longer lifetimes (i.e., the third quartile in the database).

\footnotetext{
12 The average lifetimes of measures installed in programs in the residential sector and in the commercial/industrial/agricultural sector are 11.6 and 12.5 years respectively.
} 
States and regions (e.g., Pacific Northwest, New England, California) that have offered efficiency programs for several decades have devoted significant resources to evaluation, measurement and verification $(\mathrm{EM} \& \mathrm{~V})$ activities (e.g., developed comprehensive EM\&V protocols, robust technical reference manuals). Their EM\&V practices often include frequent updates to savings estimates, measure lifetimes and, to a lesser extent, measure costs. In many cases, these updates result in lower estimates of annual or lifetime savings (e.g., reducing the assumed operating hours or measure life of high-efficiency lighting), which - all else being equal - will result in a higher total cost of saved electricity value.

\section{Policy Implications and Conclusions}

The program administrator and total cost of saved energy are valuable metrics that resource planners, regulators and stakeholders can use to approximate and compare the relative costs among demand- and supply-side investments. Both the program administrator and total cost of saved energy serve as benchmarks for comparing the cost of efficiency across utilities, states, and regions by program, sector or portfolio and identify opportunities for improvements in performance. This study is based on the most expansive and detailed collection to date of total costs for efficiency programs funded by utility customers.

Our estimate of the savings-weighted average cost of saved electricity of $\$ 0.046$ for 20 states, which compares favorably with energy supply costs and retail rates. For the residential sector, the average total cost of saved electricity on a savings-weighted basis was $\$ 0.030$ per $\mathrm{kWh}$, for the subset of programs with claimed savings. Residential product rebate programs-especially lighting programs with an average total cost of $\$ 0.018$ per $\mathrm{kWh}$ - were a primary driver of these results. If residential lighting-only programs were excluded to test the effect on the rest of the 
portfolio, the savings-weighted average total cost would have been $\$ 0.055$ per $\mathrm{kWh}$ in the residential sector ( 72 percent higher) and $\$ 0.054$ per $\mathrm{kWh}$ for all sectors (18 percent higher) for the programs in our dataset. These results illustrate the prominent role that residential lighting programs have played in utility efficiency activities to date.

For the non-residential sector, the savings-weighted, average total cost of saved electricity was $\$ 0.053$ per $\mathrm{kWh}$, for programs with claimed savings. Prescriptive C\&I rebate programs $(\$ 0.045 / \mathrm{kWh})$ and custom C\&I rebate programs $(\$ 0.052 / \mathrm{kWh})$ account for more than 60 percent of the savings in the non-residential sector.

Cost performance among program types varied more in the residential sector than in the nonresidential sector, with the inter-quartile range differing by a factor of three to five among various types of residential programs and by a factor of two for most types of non-residential programs. Understanding and taking account of this heterogeneity is important for large-scale energy and environmental policy planning and implementation that incorporate energy efficiency. This is especially the case at the national level, with recently published federal regulations for reducing $\mathrm{CO} 2$ emissions from electric power generation as a prime example. ${ }^{13}$ Energy efficiency is a voluntary compliance mechanism in this regulatory framework and may serve as part of a state's least-cost strategy to directly (under a rate-based approach) or indirectly (under a mass-based approach) meet the new, proposed federal emissions requirements.

To date, however, estimates of efficiency cost performance have generally been highly aggregated, which, as the results reported in this study demonstrate, masks considerable variation. While energy efficiency can help meet federal requirements to reduce $\mathrm{CO} 2$ emissions

\footnotetext{
${ }^{13}$ http://www2.epa.gov/carbon-pollution-standards
} 
at low cost, states have many program options to choose from and may trade energy efficiency Emission Rate Credits within and across states. Thus, both inter- and intra-state heterogeneity in efficiency cost performance must be incorporated into both implementation planning and, in the future, compliance evaluation.

Our findings indicate that at the portfolio level, efficiency can be cost competitive with supply alternatives. Moreover, comparison of the program administrator cost of saved energy with the total cost of saved energy can indicate the degree to which program administrator spending can leverage investment by participants. The relative distribution of costs between the program and its participants can be an indicator of barriers to investment in efficiency and suggest the balance of societal interest versus private interest in the benefits of saving energy. When spending is aggregated across all programs, we find that program administrators and participants are splitting the costs of efficiency almost exactly in half. Program administrators tend to contribute more for residential programs, particularly those promoting comprehensive, multi-measure approaches to efficiency in new and existing homes - projects that can require a household to make a large investment (e.g., $\$ 5,000-\$ 15,000$ per household). Administrators in a number of states are testing and implementing alternative program designs (e.g., on-bill financing, Property Assessed Clean Energy (PACE) that attempt to facilitate comprehensive building retrofits and obtain a greater cost contribution from participating customers. If successful, these financing programs may lower the program administrator's cost of saved energy and leverage ratepayer dollars.

Our results also strongly indicate the need for more consistent, reliable and complete reporting on the costs of and savings from efficiency programs. For example, program administrators in fewer than half of states with efficiency programs report total costs. Where full costs are reported, differing definitions and interpretations of the components of total costs can make it 
challenging to aggregate and compare data. Accurate and consistent reporting of participant costs and lifetime savings is particularly important. Reducing the uncertainty associated with these factors could substantially increase confidence in efficiency among planners, regulators, and policymakers. Finally, ensuring that program administrators report claimed energy savings in a consistent fashion and that savings last as long as program administrators assume is also critical for estimating emissions reductions and trading energy efficiency emission rate credits. ${ }^{14}$ Continued efforts to establish more consistent reporting would better establish the cost effectiveness and potential of efficiency as an energy resource, as well as provide more accurate insights into programs, policies and system needs.

\section{Acknowledgements}

This work was funded by the National Electricity Delivery Division of the U.S. Department of Energy's Office of Electricity Delivery and Energy Reliability and the Office of Energy Policy and Systems Analysis under Lawrence Berkeley National Laboratory Contract No. DE-AC0205CH11231. The authors express their gratitude to our reviewers, who are too numerous to name here; their input improved our analysis and this summary of the results.

\section{References}

Allcott, H. and T. Rogers 2014. "The Short-Run and Long-Run Effects of Behavioral Interventions: Experimental Evidence from Energy Conservation" American Economic Review 2014, 104(10): 3003-3037 http://dx.doi.org/10.1257/aer.104.10.3003.

Barbose, G. L., C.A. Goldman, I. M. Hoffman, M. A. Billingsley. 2013. The Future of Utility Customer-Funded Energy Efficiency Programs in the United States: Projected Spending and Savings to 2025. January. LBNL-5803E.

Billingsley, M., I. M. Hoffman, E. Stuart, S. R. Schiller, C. A. Goldman, and K. Hamachi LaCommare. 2014. "The Program Administrator Cost of Saved Energy for Utility Customer-Funded Energy Efficiency Programs.” Lawrence Berkeley National Laboratory. LBNL-6595E. April 2014.

\footnotetext{
${ }^{14}$ Program administrators and evaluators can also utilize and leverage investments in advanced metering infrastructure (e.g., utility bills with hourly interval data before and after retrofits) may help to provide more robust estimates of savings and reduce EM\&V costs.
} 
Consortium for Energy Efficiency (CEE). 2016. 2015 State of the Efficiency Program Industry Report: Budgets, Expenditures, and Impacts. March.. http://www.cee1.org/annualindustry-reports

Energy and Resource Solutions (ERS) 2014. Savings Estimation Technical Reference Manual for the California Municipal Utilities Association. May 42014.

Eto, J., E. Vine, L. Shown, R. Sonnenblick, and C. Payne 1996. "The Total Cost and Measured Performance of Utility-Sponsored Energy Efficiency Programs.” The Energy Journal 17 (1).

Friedrich, K., Eldridge, M., York, D., Witte, P. and Kushler, M. 2009. "Saving Energy CostEffectively: A National Review of The Cost of Energy Saved Through Utility-Sector Energy Efficiency Programs.” American Council for an Energy-Efficient Economy (ACEEE). September. Report Number U092, September.

Hayes, S., S. Nadel, M. Kushler, and D. York 2011. "Carrots for Utilities: Providing Financial Returns for Utility Investments in Energy Efficiency.” American Council for an EnergyEfficient Economy. Report U111. January 2011.

Hirst, E. and C. A. Goldman 1990. "Review of Demand-Side Data Needs for Least-Cost Utility Planning.” Energy 15(5): 403-411. 1990.

Hoffman, Ian M., S.R. Schiller, A. Todd, M.A. Billingsley, C.A. Goldman, L.C. Schwartz 2015. "Energy Savings Lifetimes and Persistence: Practices, Issues and Data" Lawrence Berkeley National Laboratory. May 2015. https://emp.lbl.gov/publications/energy-savings-lifetimes

Hoffman, Ian M., G.M. Rybka, G. Leventis, C.A. Goldman, L.C. Schwartz, M.A. Billingsley, and S.R. Schiller 2015. "The Total Cost of Saving Electricity through Utility CustomerFunded Energy Efficiency Programs: Estimates at the National, State, Sector and Program Level" Lawrence Berkeley National Laboratory. April 2015. https://emp.lbl.gov/publications/total-cost-saving-electri

Itron Consulting 2014. "2010-2012 WO017 Ex Ante Measure Cost Study Final Report." Submitted to the California Public Utilities Commission. May 2014.

Joskow, P. and D. B. Marron 1992. "What Does a Negawatt Really Cost? Evidence from Utility Conservation Programs." The Energy Journal 13 (4): 41-74.

Khawaja, M. S. and J. Stewart 2014. "Long-Run Savings and Cost-Effectiveness of Home Energy Reports Programs" Cadmus Group Inc. October 2014. http://www.cadmusgroup.com/wpcontent/uploads/2014/11/Cadmus_Home_Energy_Reports_Winter2014.pdf.

Krause, Florentin, and Joseph H. Eto. 1988. Least Cost Utility Planning, A Handbook for Public Utility Commissioners Volume 2, The Demand-Side: Conceptual and Methodological 
Issues. Report prepared by Lawrence Berkeley National Laboratory for the National Association of Regulatory Utility Commissioners, Washington, DC: December.

Meier, A. K. 1982. Supply Curves of Conserved Energy, Lawrence Berkeley National Laboratory, LBL-14686. May.

Meier, A. K. 1984. The Cost of Conserved Energy as an Investment Statistic. Lawrence Berkeley National Laboratory. ESL-IE-84-04-109.

Molina, M. 2014. "The Best Value for America's Energy Dollar: A National Review of the Cost of Utility Energy Efficiency Programs." American Council for an Energy-Efficient Economy. March 2014. Report Number U1402.

National Action Plan for Energy Efficiency (NAPEE). 2007. Model Energy Efficiency Program Impact Evaluation Guide. Prepared by Steven R. Schiller, Schiller Consulting, Inc.

Sant, R. W. 1979. The Least-Cost Energy Strategy: Minimizing Customer Costs Through Competition. The Energy Productivity Center, Mellon Institute, Arlington, Virginia.

Schiller, S.R., C.A. Goldman and E. Galawish 2011. "National Energy Efficiency Evaluation, Measurement and Verification (EM\&V) Standard: Scoping Study of Issues and Implementation Requirements" Commissioned by the Evaluation, Measurement and Verification Working Group of the State and Local Energy Efficiency Action Network (SEE Action). April 2011

Ting, M. 2014. “California Measure Cost Study.” DOE SEE Action Webinar, September 2014. 


\section{Tables and Figures - Hoffman et al. Cost of Saved Energy}

Figure 1. Map of states in which total costs were available and collected for one or more program administrators.

Figure 2. Total cost of saved electricity for all market sectors

Figure 3. Savings-weighted average, median and interquartile range of total cost of saved electricity values for all sectors for programs with claimed savings

Figure 4. Total cost of saved electricity for various types of residential programs

Figure 5. Savings-weighted average, median and interquartile range for the total cost of saved electricity for various residential program types.

Figure 6. Total cost of saved electricity for various commercial, industrial and agricultural program types

Figure 7. Savings-weighted average, median value and interquartile range for total cost of saved electricity for non-residential program types 5

Figure 8. Savings-weighted average total cost of saved electricity by state.

Figure 9. The impact of program lifetimes on the levelized total cost of saved energy for select program types

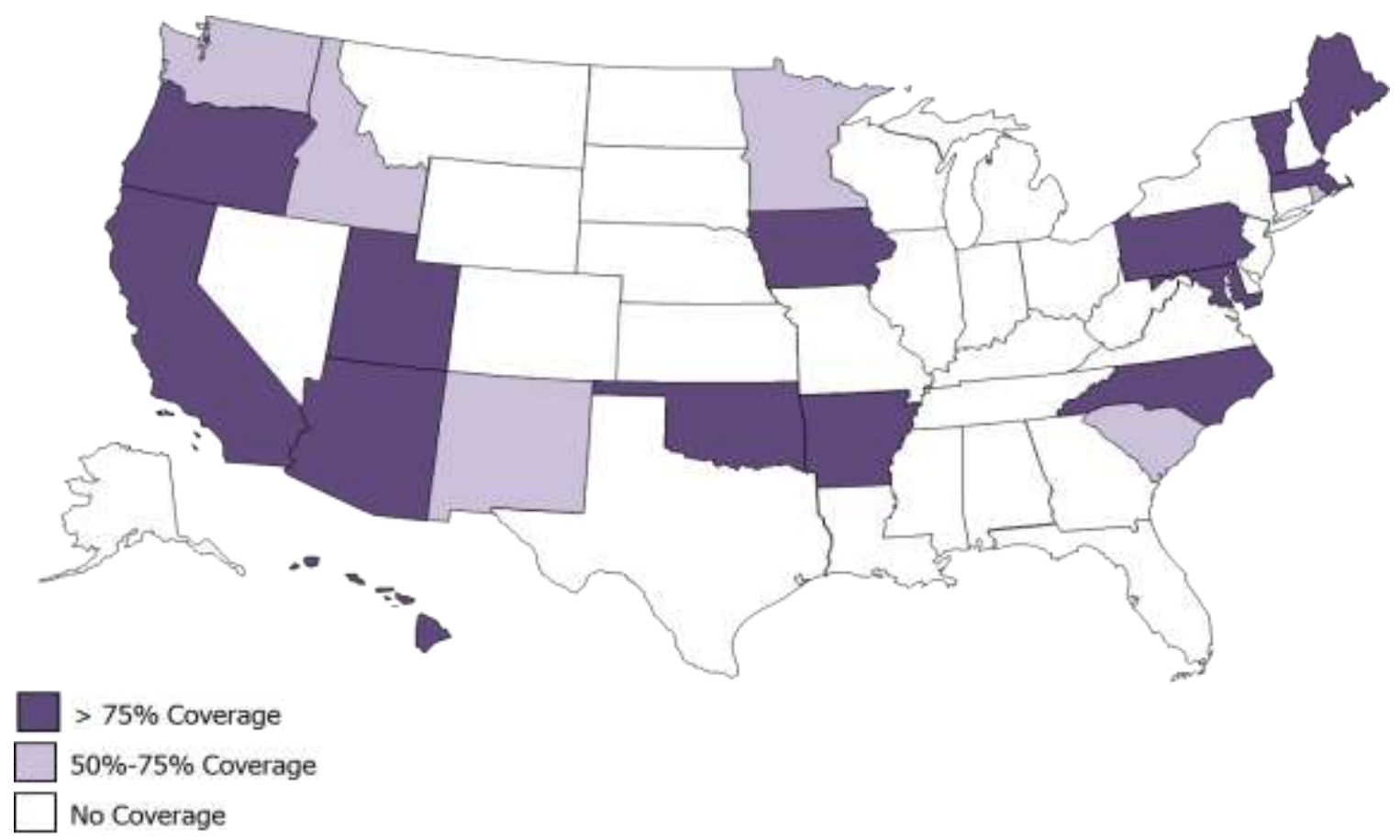

Figure 1. Map of states in which total costs were available and collected for one or more program administrators 


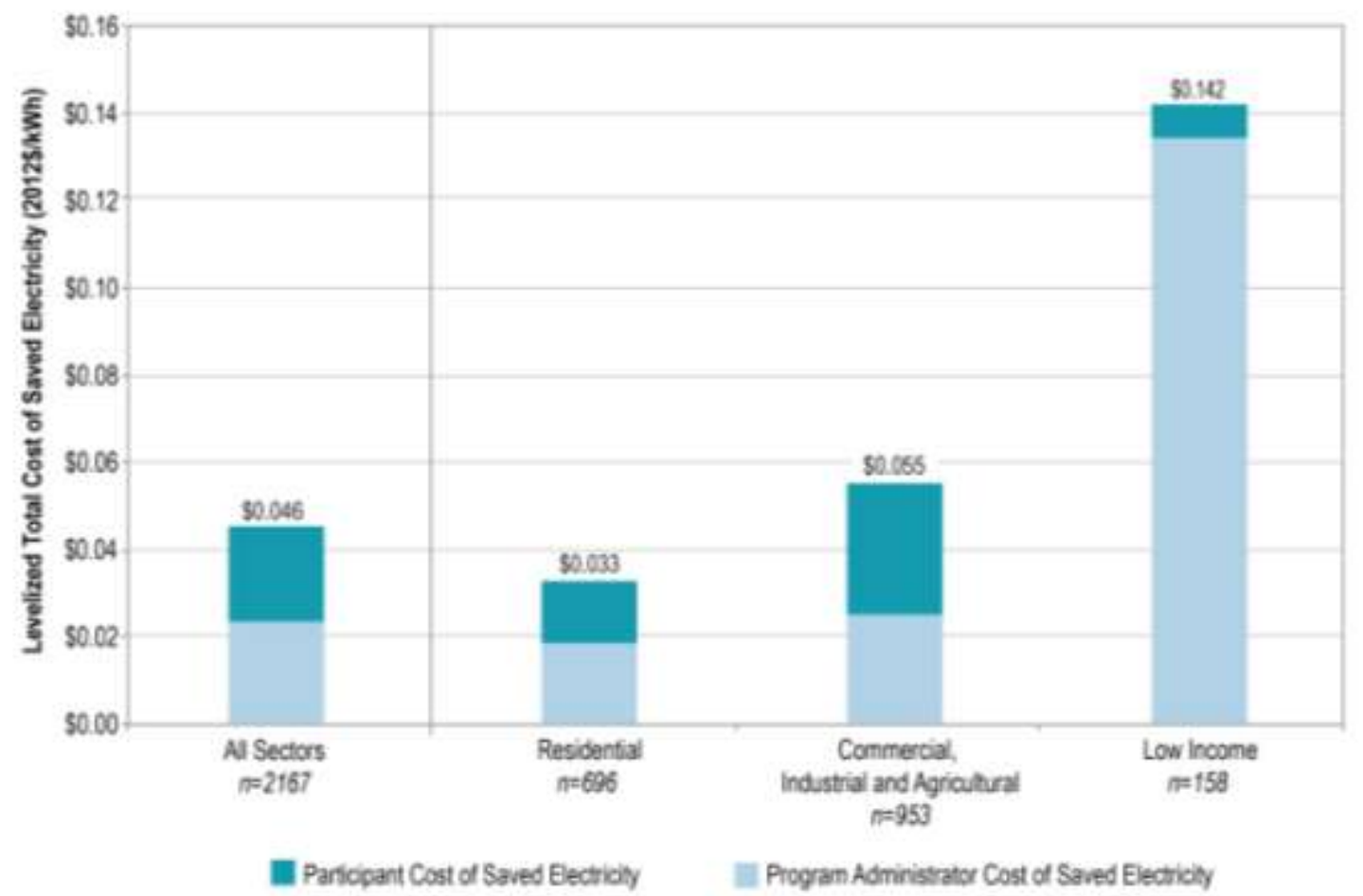

Figure 2. Total cost of saved electricity for all market sectors

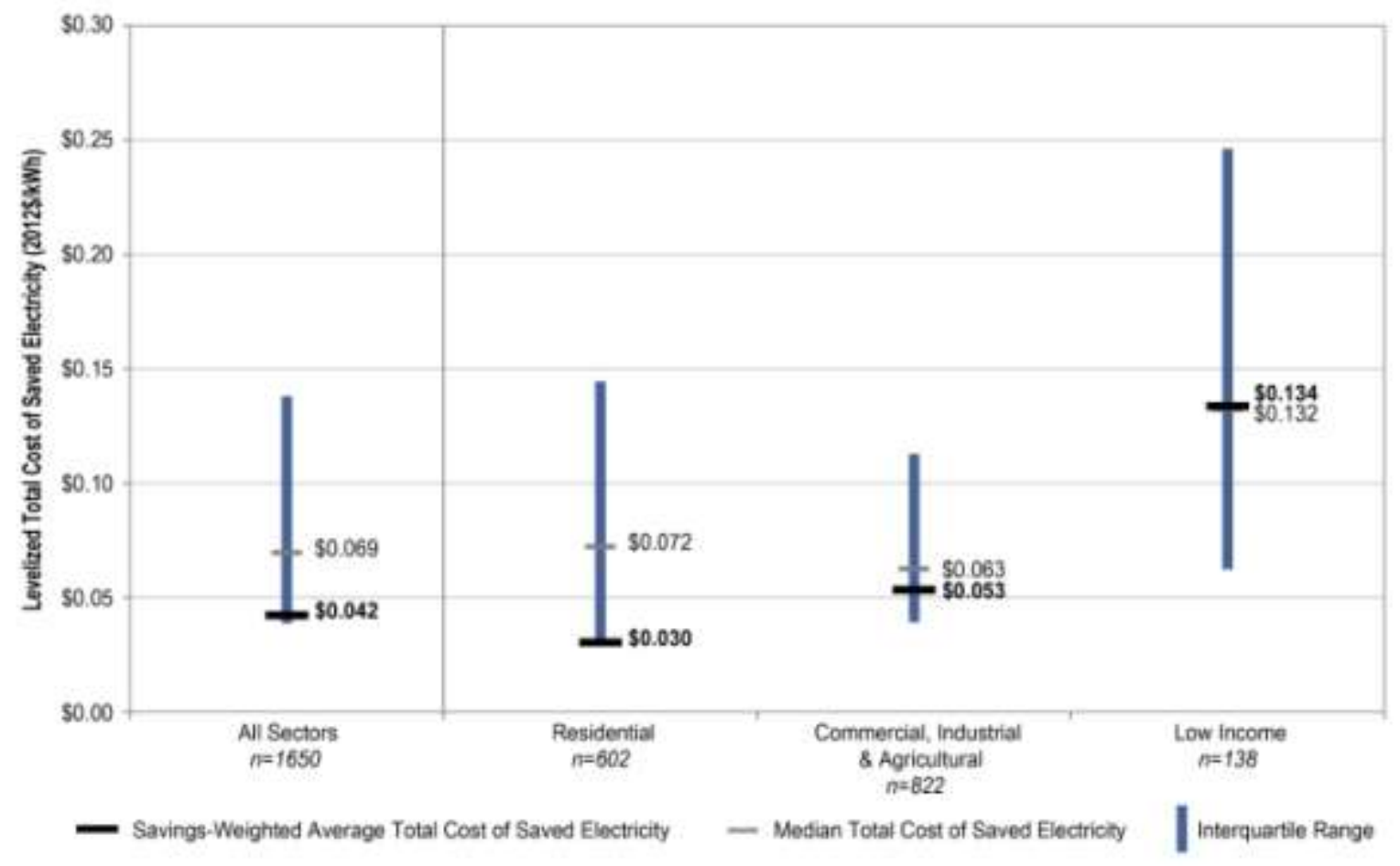

Figure 3. Savings-weighted average, median and interquartile range of total cost of saved electricity values for all sectors for programs with claimed savings 


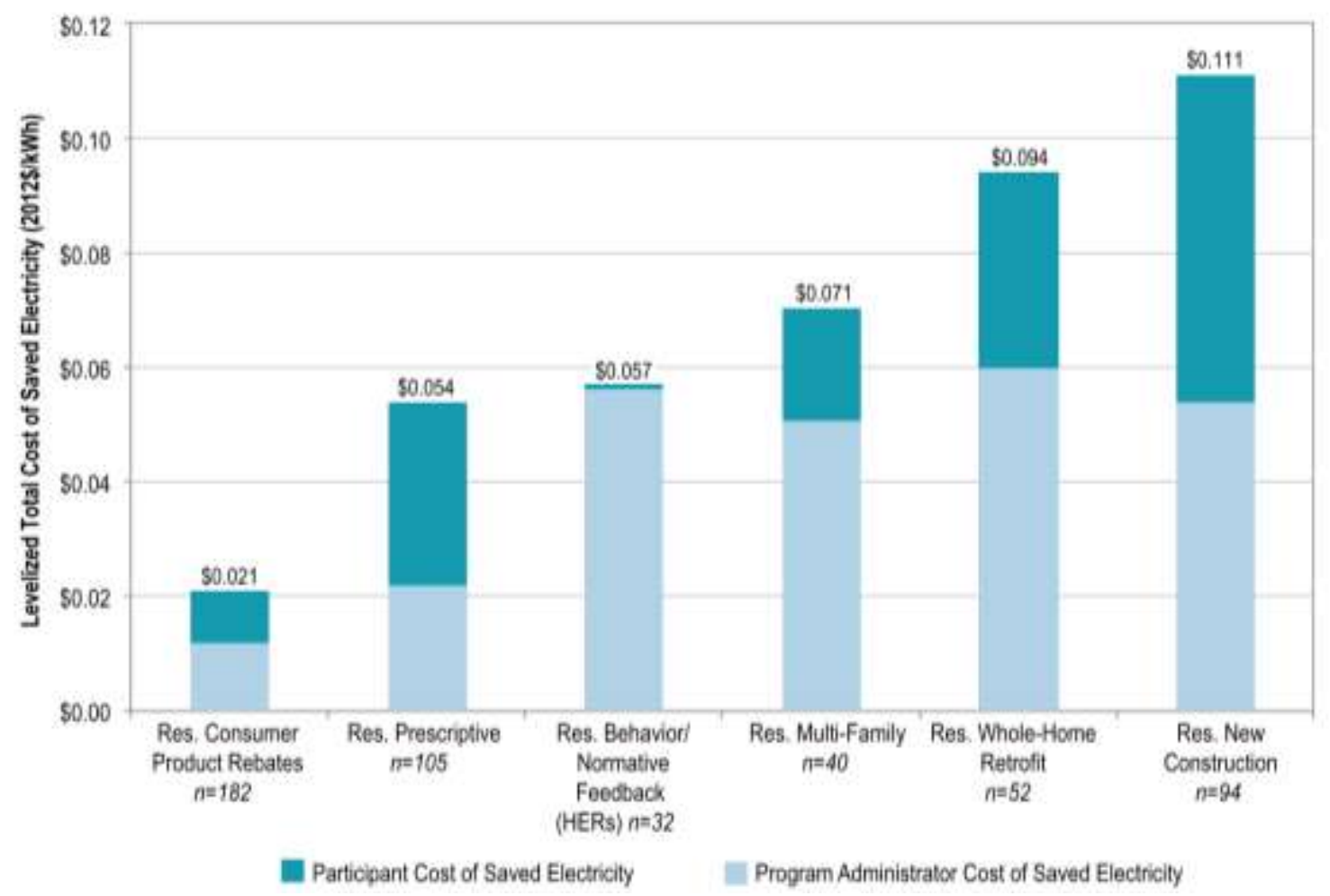

Figure 4. Total cost of saved electricity for various types of residential programs 


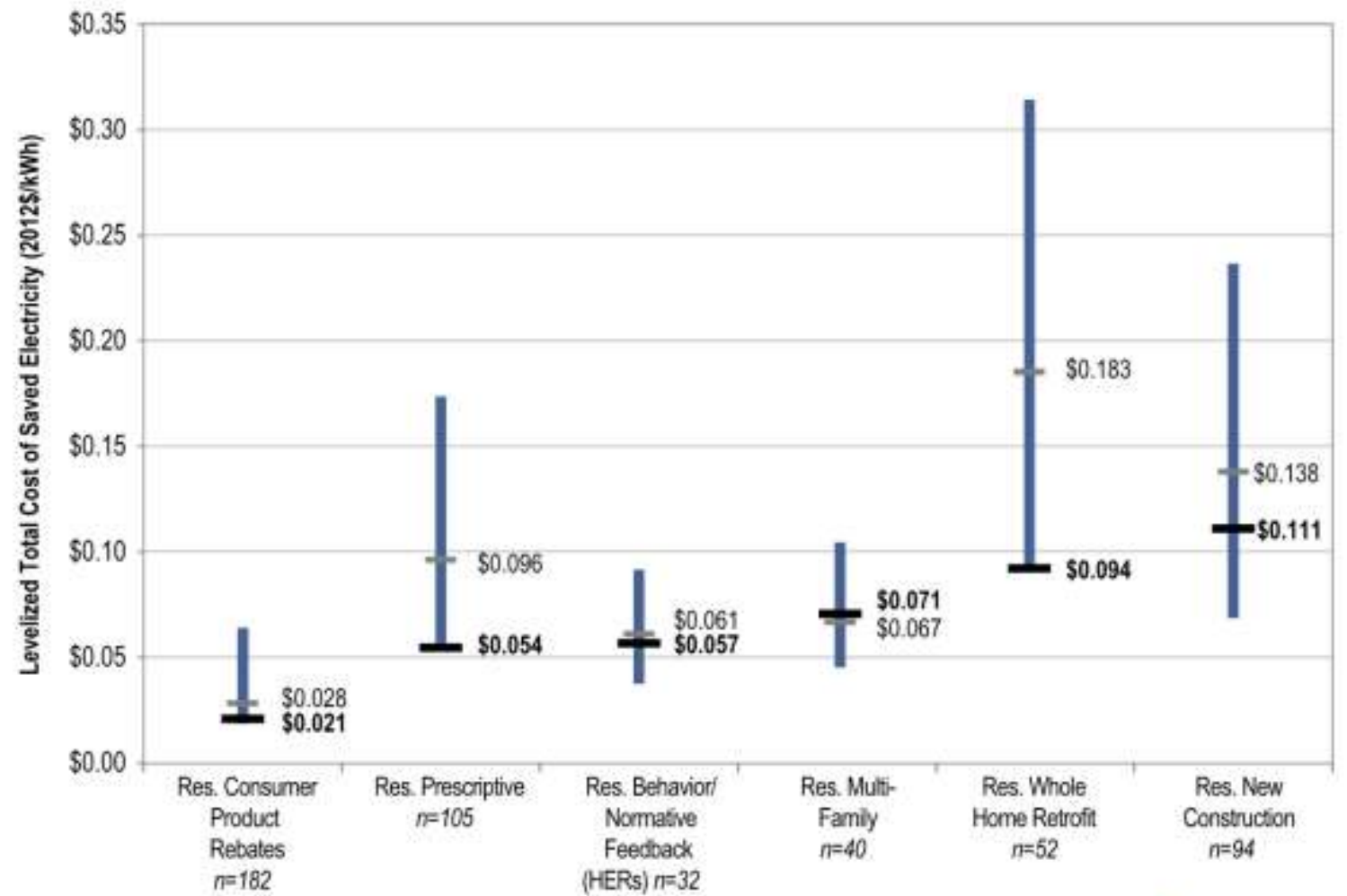

Savings-Weighted Average Total Cost of Saved Electricity - Median Total Cost of Saved Electricity

Interquartile Range

Figure 5. Savings-weighted average, median and interquartile range for the total cost of saved electricity for various residential program types

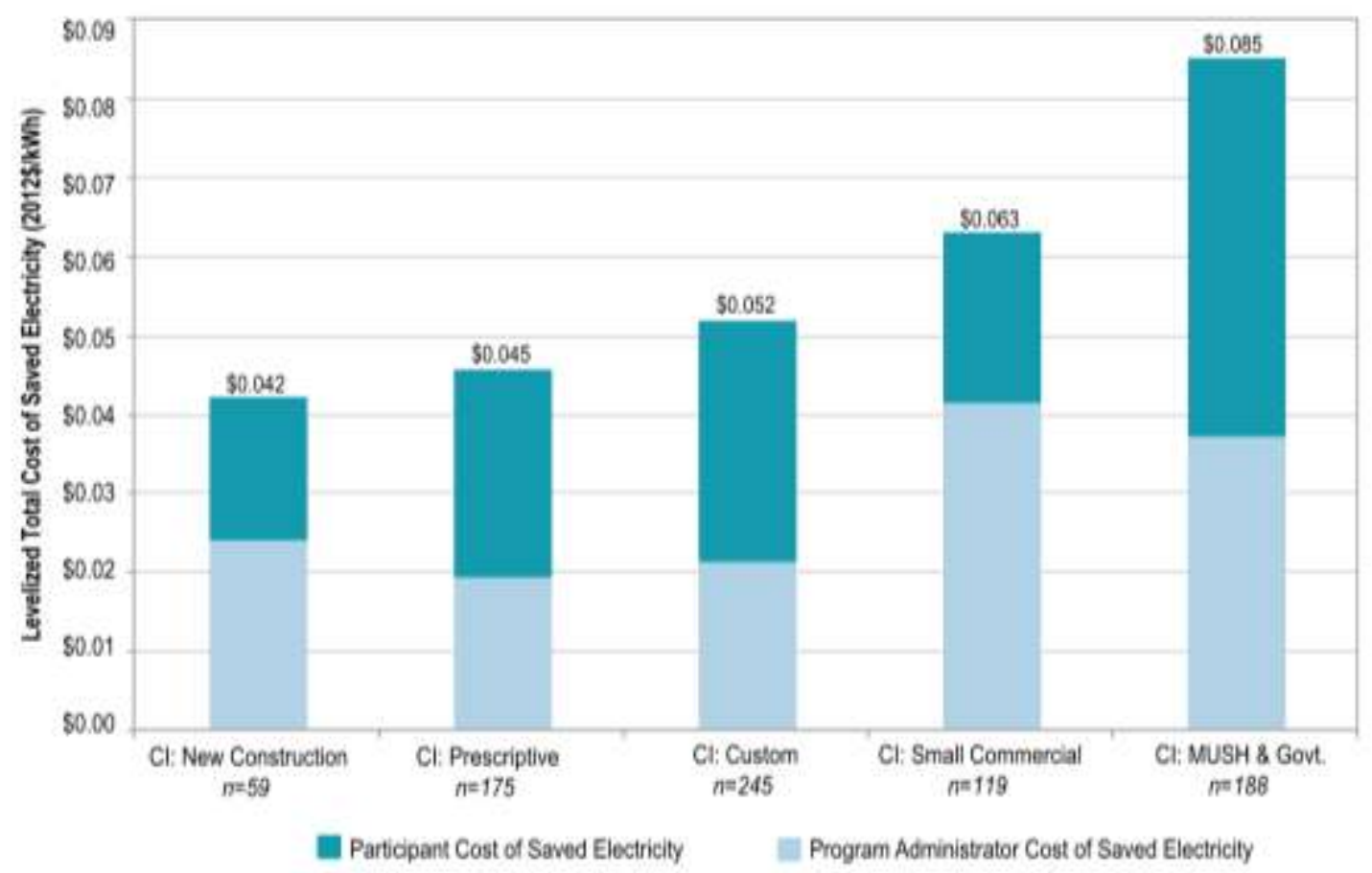


Figure 6. Total cost of saved electricity for various commercial, industrial and agricultural program types

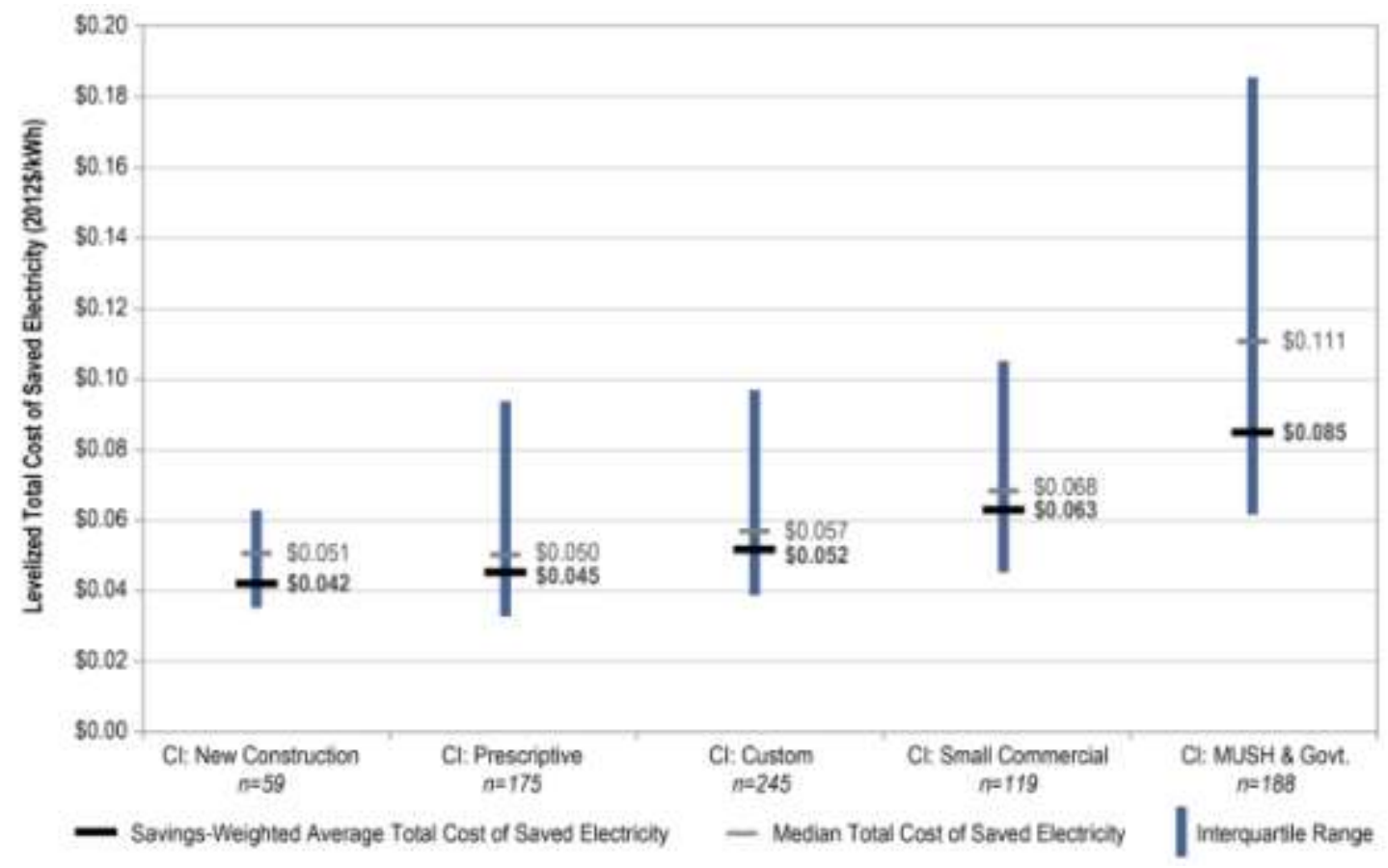

Figure 7. Savings-weighted average, median value and interquartile range for total cost of saved electricity for non-residential program types 


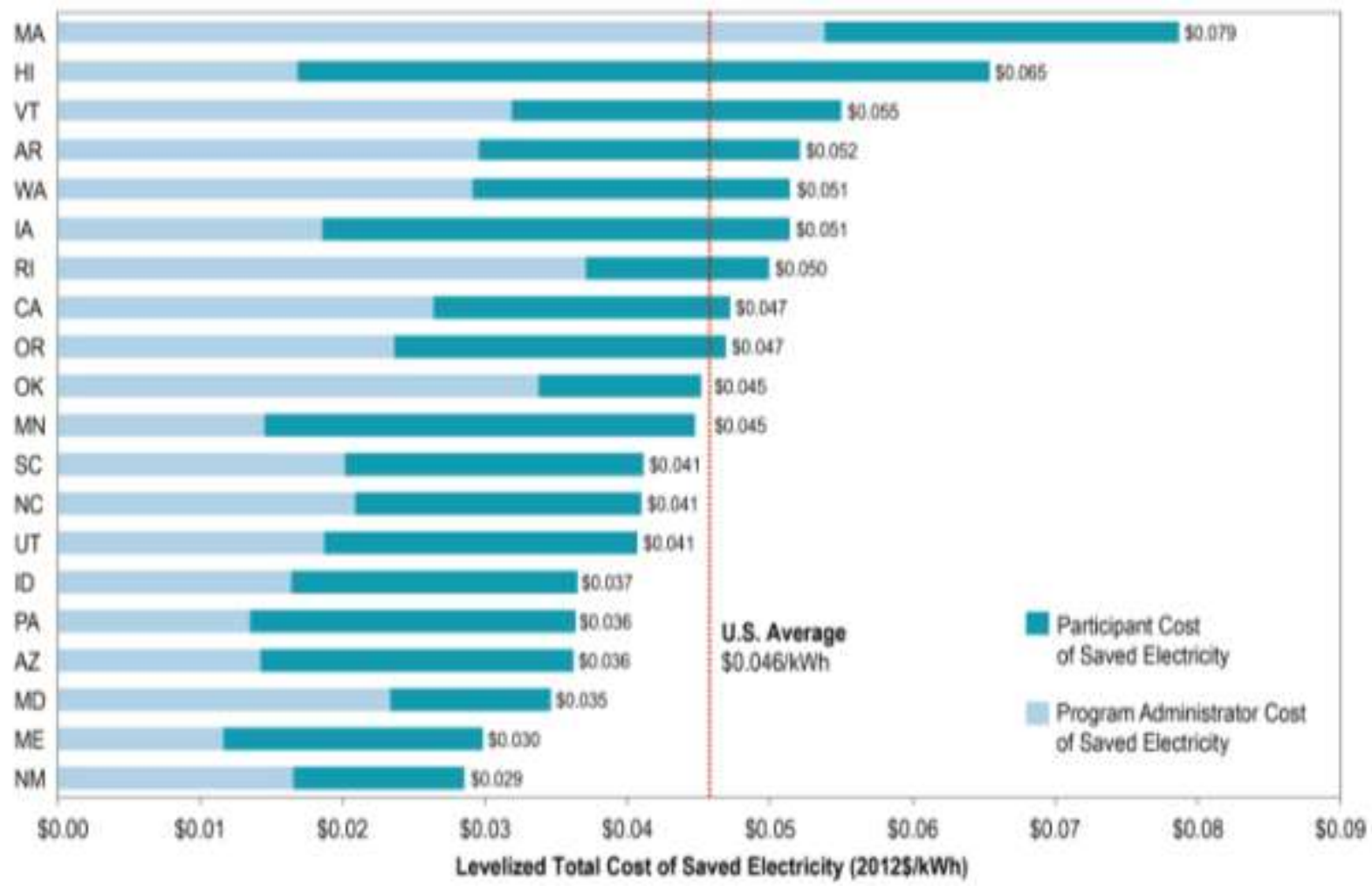

Figure 8. Savings-weighted average total cost of saved electricity by state 


\section{Table 1. Lifetimes for various types of efficiency programs as reported by program administrators}

\begin{tabular}{|c|c|c|c|c|}
\hline Program Type & $\begin{array}{l}\text { 1st Quartile } \\
\text { (years) }\end{array}$ & $\begin{array}{l}\text { Simple } \\
\text { Average } \\
\text { (years) }\end{array}$ & $\begin{array}{l}\text { 3rd Quartile } \\
\text { (years) }\end{array}$ & $\begin{array}{c}\text { Number of } \\
\text { program } \\
\text { years used to } \\
\text { derive values }\end{array}$ \\
\hline R: Appliance Recycling & 5 & 7 & 9 & 58 \\
\hline $\begin{array}{l}\text { R: Behavior/Normative } \\
\text { Feedback (HERs) }\end{array}$ & 1 & 1 & 1 & 17 \\
\hline $\begin{array}{l}\text { R: Consumer Product } \\
\text { Rebate/Lighting }\end{array}$ & 6 & 7 & 7 & 89 \\
\hline R: New Construction & 14 & 25 & 20 & 107 \\
\hline $\begin{array}{l}\text { R: Whole Home } \\
\text { Upgrade/Retrofit }\end{array}$ & 11 & 15 & 17 & 136 \\
\hline Low Income & 9 & 13 & 15 & 133 \\
\hline Cl: Custom & 10 & 12 & 15 & 256 \\
\hline Cl: MUSH \& Govt. & 10 & 12 & 14 & 157 \\
\hline Cl: New Construction & 14 & 15 & 16 & 70 \\
\hline $\mathrm{Cl}$ : Prescriptive & 10 & 12 & 15 & 184 \\
\hline
\end{tabular}

Notes: $\mathrm{Cl}$ signifies commercial, agricultural and industrial programs; $R$, residential programs; MUSH is Municipalities, Universities, Schools and Hospitals. Values are rounded to the nearest integer.

Source: LBNL DSM Program Database 2014

\footnotetext{
${ }^{1}$ These lifetime estimates are based on annual efficiency program reports to regulators. During this time period (2009-2012), many behavioral or normative feedback programs were pilots and an assumed measure lifetime of one year was typically used (or no savings were claimed). Khawaja and Stewart (2014) present more up-to-date estimates of lifetime savings for normative behavior programs, which we include as a sensitivity in the COSE calculation in Figure 9.
} 


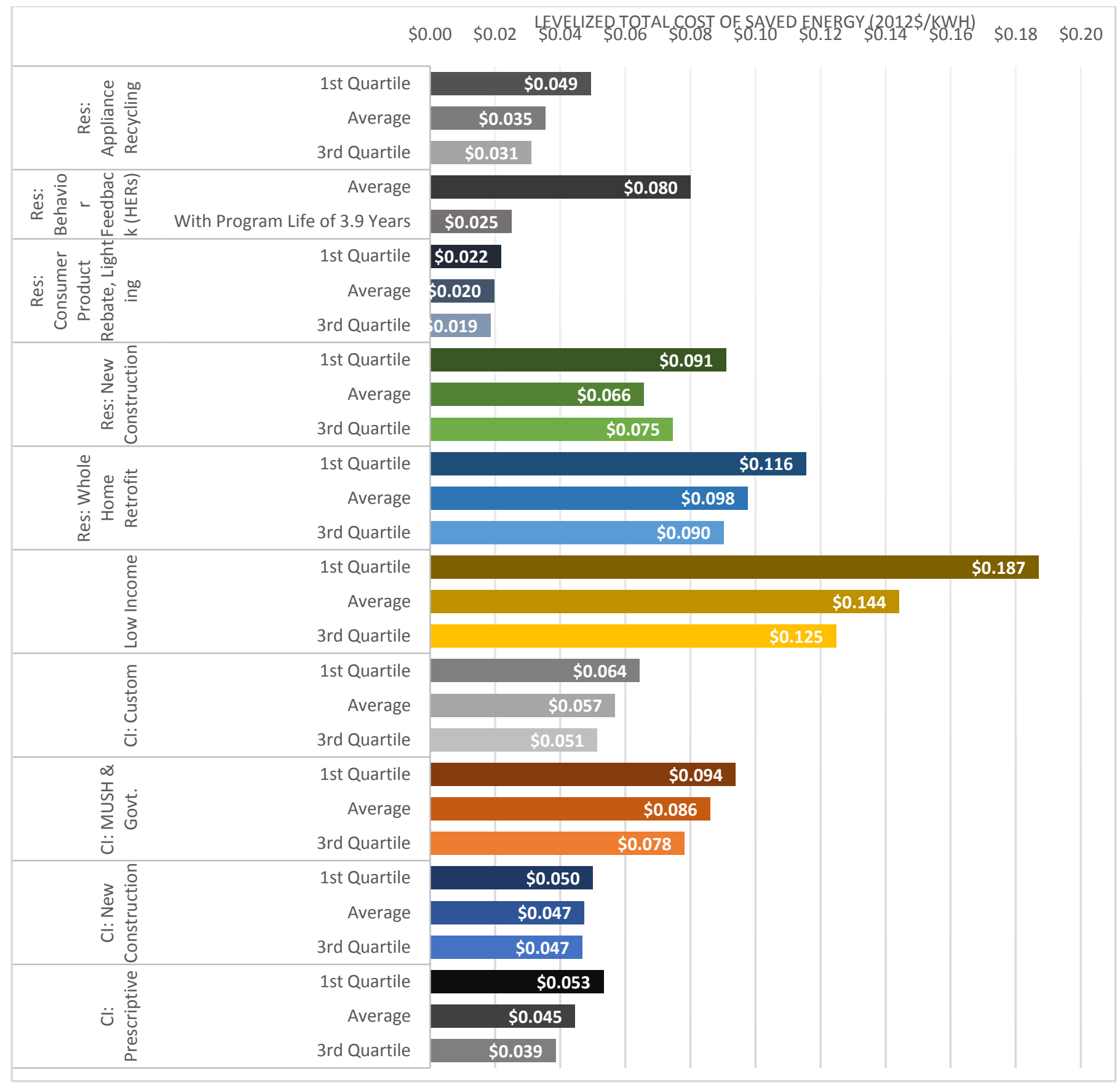

\section{Figure 9. The impact of program lifetimes on the levelized total cost of saved energy for select program types}

Note: LBNL calculated the total cost of saved electricity values in this graph using program savings lifetimes reported by energy efficiency program administrators. The bar labeled $1^{\text {st }}$ Quartile denotes the calculated cost of saved energy for programs with shorter reported lifetimes (those at the $25^{\text {th }}$ percentile of all reported lifetimes). The $3^{\text {rd }}$ Quartile is the calculated cost for programs with longer reported savings lifetimes (at the $75^{\text {th }}$ percentile). 